\title{
Rare Earth Elements: A brief overview
}

\author{
Agnieszka Drobniak and Maria Mastalerz \\ Indiana Geological and Water Survey, Indiana University, Bloomington, Indiana \\ E-mail: agdrobni@iu.edu \\ Received: 11/29/2021 \\ Accepted for publication: 01/04/2022 \\ Published: 01/2022 \\ Suggested citation: Drobniak, A., and Mastalerz, M., 2022, Rare Earth Elements-A brief overview: Indiana Geological and Water \\ Survey, Indiana Journal of Earth Sciences, v. 4. DOI 10.14434/ijes.v4i1.33628.
}

\begin{abstract}
Recent years have witnessed an increasing awareness and interest in rare earth elements (REE). These several, usually unfamiliar elements are key components of countless products used in our daily lives. Because of their use in many modern technologies, including those critical for national security, the demand for REEs grows, and so does their production and the need to find new sources and to improve their extraction. This article provides an overview of REEs, their availability, production, and uses, and briefly discusses the future of these valuable and critical metals.
\end{abstract}

\section{WHAT ARE THE RARE EARTH ELEMENTS?}

Called the "rare earth metals," "technology metals," or "seeds of technology," the rare earth elements (REE) are a group of 15 lanthanides plus scandium and yttrium (Figure 1). They share similar geochemical properties and are often found together in geologic formations.
Based on atomic number, they are divided into the light group or cerium group (LREE), and the heavy group known also as the yttrium group (HREE). Heavy REEs are less common, which typically makes them more desired and valued. REEs are also often referred to as "rare earth oxides" because they are typically sold as oxide

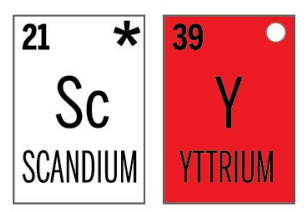

39 Atomic number
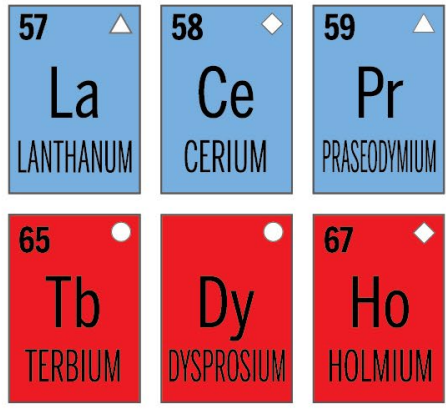
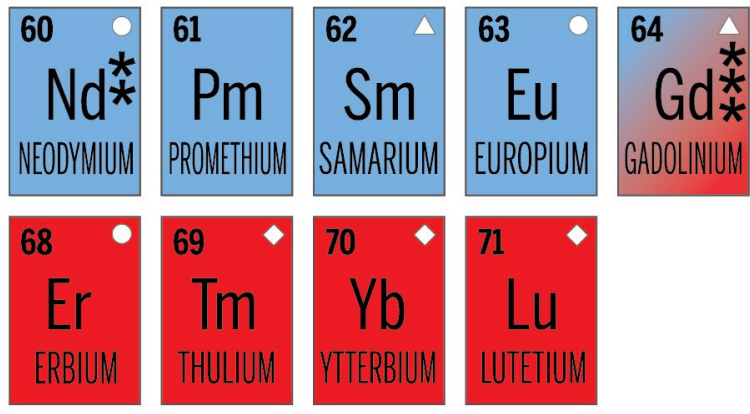

Light REE

Heavy REE

* Included with REE $\quad * *$ Does not occur in nature $\quad * * *$ IUPAC Light REE, USGS Heavy REE

$\bigcirc$ Critical REE (Y, Nd, Eu, Tb, Dy, Er) $\quad \triangle$ Uncritical REE (La, Pr, Sm, Gd) $\diamond$ Excessive REE (Ce, Ho, Tm, Yb, Lu)

Figure 1. List and classification of rare earth elements (modified from Mastalerz et al., 2020 and USGS, 2021a). 
compounds (Balaram, 2019; King, 2021; Mastalerz et al., 2020; USGS, 2014).

Despite their name, the rare earth elements (with the exception of promethium) are relatively abundant in the Earth's crust. Even lutetium (Lu), the rarest of the REEs, is about 200 times more common than gold. What makes REEs rare is the rarity of finding them in quantities supporting economical mining and extraction (USGS, 2005; USGS, 2014; Vocken, 2016).

The rare earth elements do not occur in nature as individual elements, but rather as minor or major constituents in ore-accessory minerals. Igneous and metamorphic rocks are their traditional sources, but sedimentary rocks have become of interest with growing demand. While there are more than 250 minerals that can contain REEs, economic-scale concentrations of rare earths are primarily found in carbonatites, alkaline igneous systems, ion-absorption clay deposits, and monazitexenotime-bearing placer deposits. Although other deposits can contain traces of REEs, their concentration is usually too low for profitable mining and extraction (Balaram, 2019; EPA, 2012; Mastalerz et al., 2020; USGS, 2014; Figure 2). Recently, a lot of attention has been directed toward other potential REE sources like coal mining waste and coal combustion byproducts, which could potentially supply a significant amount of REEs in many coal-mining countries, including the United States (DOE, 2021; Mastalerz et al., 2020).

\section{RARE EARTH ELEMENT USES}

Prior to the production of the first television sets in the mid-1960s, there were relatively few uses for REEs, but as new technologies were developed, demand for REEs has increased. Researchers created samarium-cobalt magnets for radar instruments, combined scandium with aluminum to increase the performance of fighter jets, and incorporated yttrium in lasers. Batteries with lanthanum and neodymium could be rechargeable and used not only in
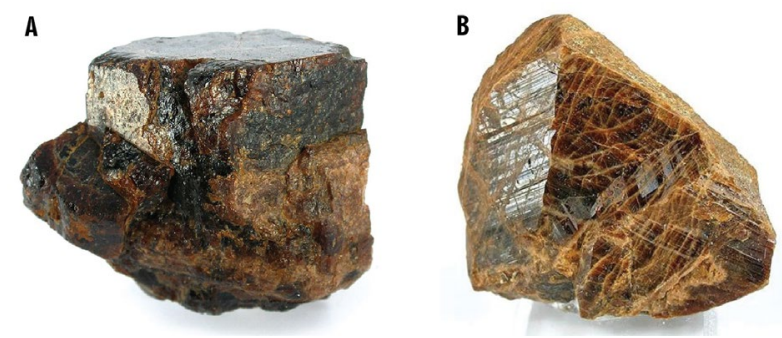

Figure 2. Photographs of REE-bearing minerals: $A$ ) bastnäsite-carbonate-fluoride mineral and (B) monazite-phosphate mineral. Photo by Rob Lavinsky, iRocks.com. portable electronics but also in hybrid cars. Neodymiumiron magnets became indispensable in electric engine starters, power windows and door locks, and windshield wiper motors. The use of REEs increased even more in the 1990s and 2000s by implementing erbium to boost the signal in fiber-optic cables and developing cellphones thanks to the use of lanthanum, neodymium, ytterbium, and erbium (Science History Institute, 2021).

Today, REEs are a critical part of our modern life, their applications are countless, and technological advancements are impossible without them. They are increasingly used in defense and telecommunication systems, electronics, transportation, chemical catalysts, and medical applications. With increased concerns about climate change and energy independence, REE uses are expected to grow, especially with high demand for hybrid and electric cars and wind turbines (Jowitt, 2018; Market Analysis Report, 2021; Voncken, 2016; Figure 3).

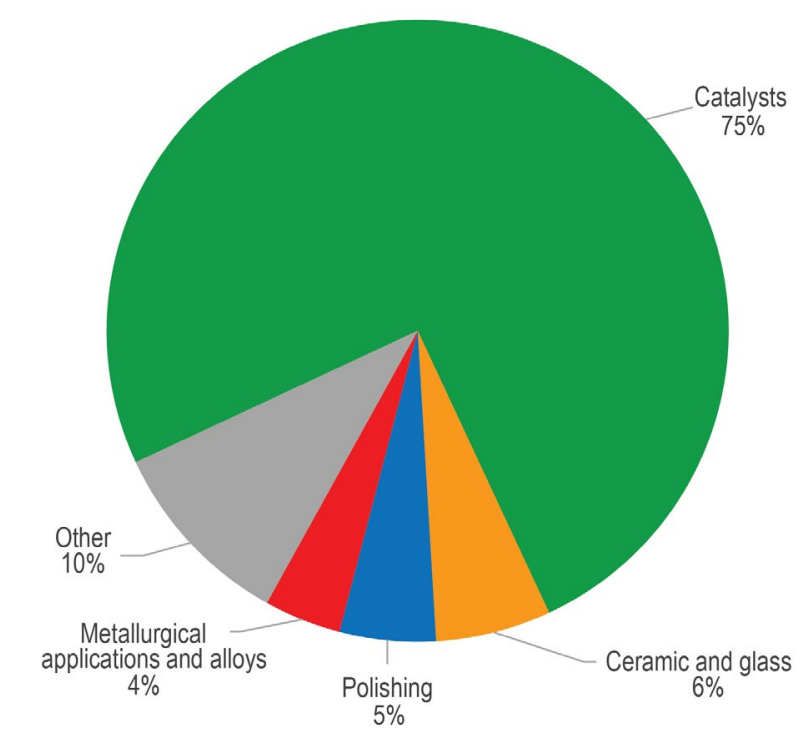

Figure 3. Pie diagram showing the distribution of rare earth elements in the United States by end use in 2020 (compiled from USGS, 2021b).

\section{GLOBAL RESERVES AND PRODUCTION OF RARE EARTH ELEMENTS}

According to the United States Geological Survey, the global reserves of rare earths are estimated at approximately 120 million metric tons (earth oxides equivalent) with China holding the largest share at about $37 \%$ (Figure 4; USGS, 2021b). 
In the 1950s and 1960s, there was limited interest in REEs, and most of the rare earth oxides were mined in South Africa, India, and Brazil. This changed when television production sparked interest and demand for REEs, as europium became an essential material to produce the red tint in color televisions. Discovered in 1949, the Mountain Pass deposit in California started production of the elements from bastnäsite, making the United States

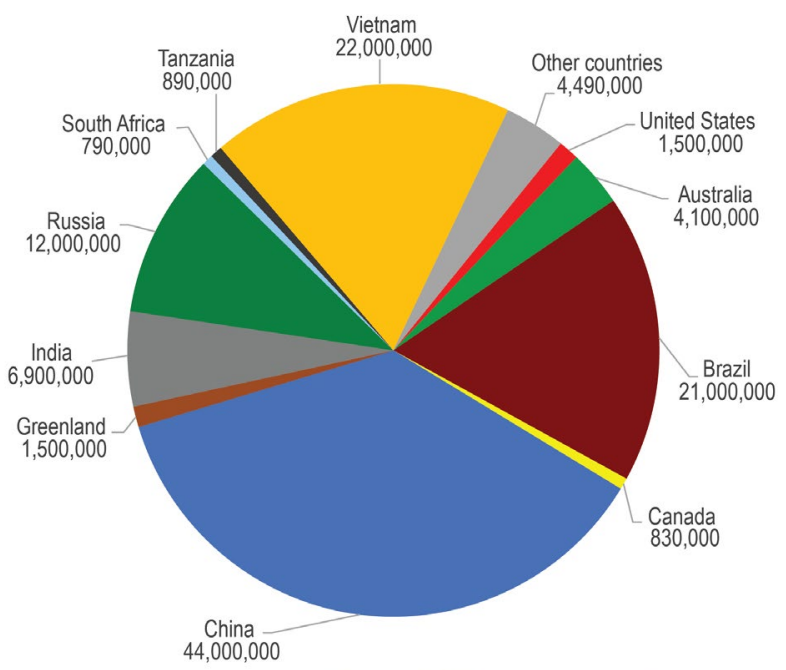

Figure 4. Pie diagram showing worldwide reserves of rare earth elements in metric tons of rare earth oxides (compiled from USGS, 2021b). a leading producer of rare earths in the world between 1965 and 1995 (King, 2021; MP Materials, 2021; Voncken, 2016).

In the late $1970 \mathrm{~s}$, China started to increase its manufacturing power and entered the global trade. Chinese industry began mining significant amounts of REEs in the early 1980s and increasing their production by about $40 \%$ each year. By the mid-1990s, China dominated the REE market. As its production kept rising, prices of REEs dropped drastically, and many companies around the world, including the American Mountain Pass Mine, were unable to compete and stopped their operations (King, 2021; Science History Institute, 2021).

As the demand for REEs started to increase dramatically, China held total control over the rare earths market. By increasing mining and buying shares of REE companies in other countries, China eventually controlled $95 \%$ of global production. This situation led to the "Rare Earth Crisis" of 2010, when a dispute between China and Japan led to restrictions of rare element exports imposed by China. Prices of REEs skyrocketed, in some cases even 500\% (King, 2021; Science History Institute, 2021; Figures 5 and 6).

BELOW: Figure 5. Bar graph showing global production of the rare earth elements (compiled from USGS, 2021ab and previous editions of the report).

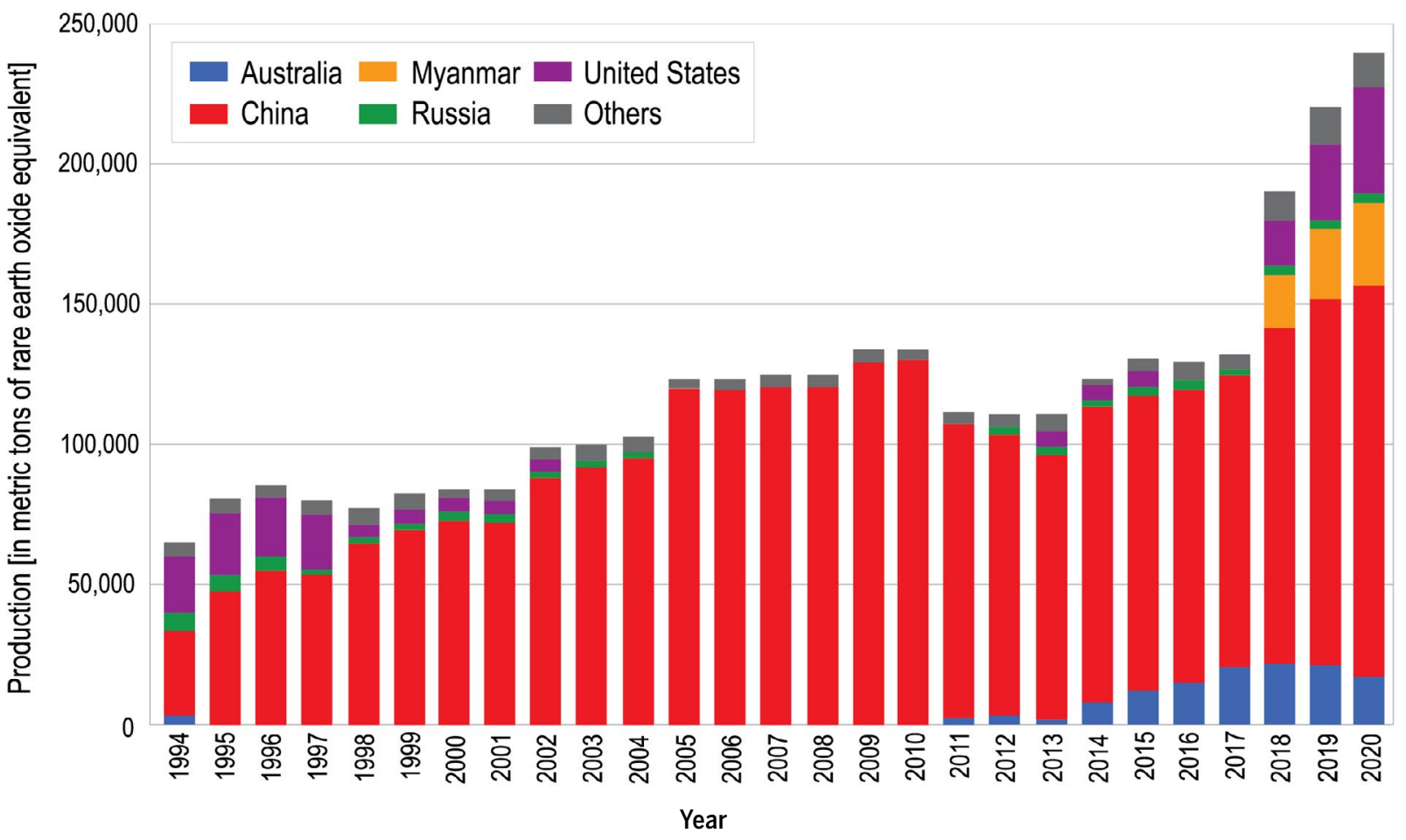


That incident forced many countries to reevaluate their REE prospects to lower dependency on China. In 2011, Australia started REE mining, followed by the United States, Canada, and later Brazil, Malaysia, Russia, Thailand, and Vietnam. While Chinese REE production still dominates the markets, the share of contribution from other countries has been slowly increasing in recent years. In 2020, the global production was estimated at 240,000 tons of rare earth oxide equivalent, with China contributing about $65 \%$ of the total supply (USGS, 2021b; Figures 5 and 6).
A
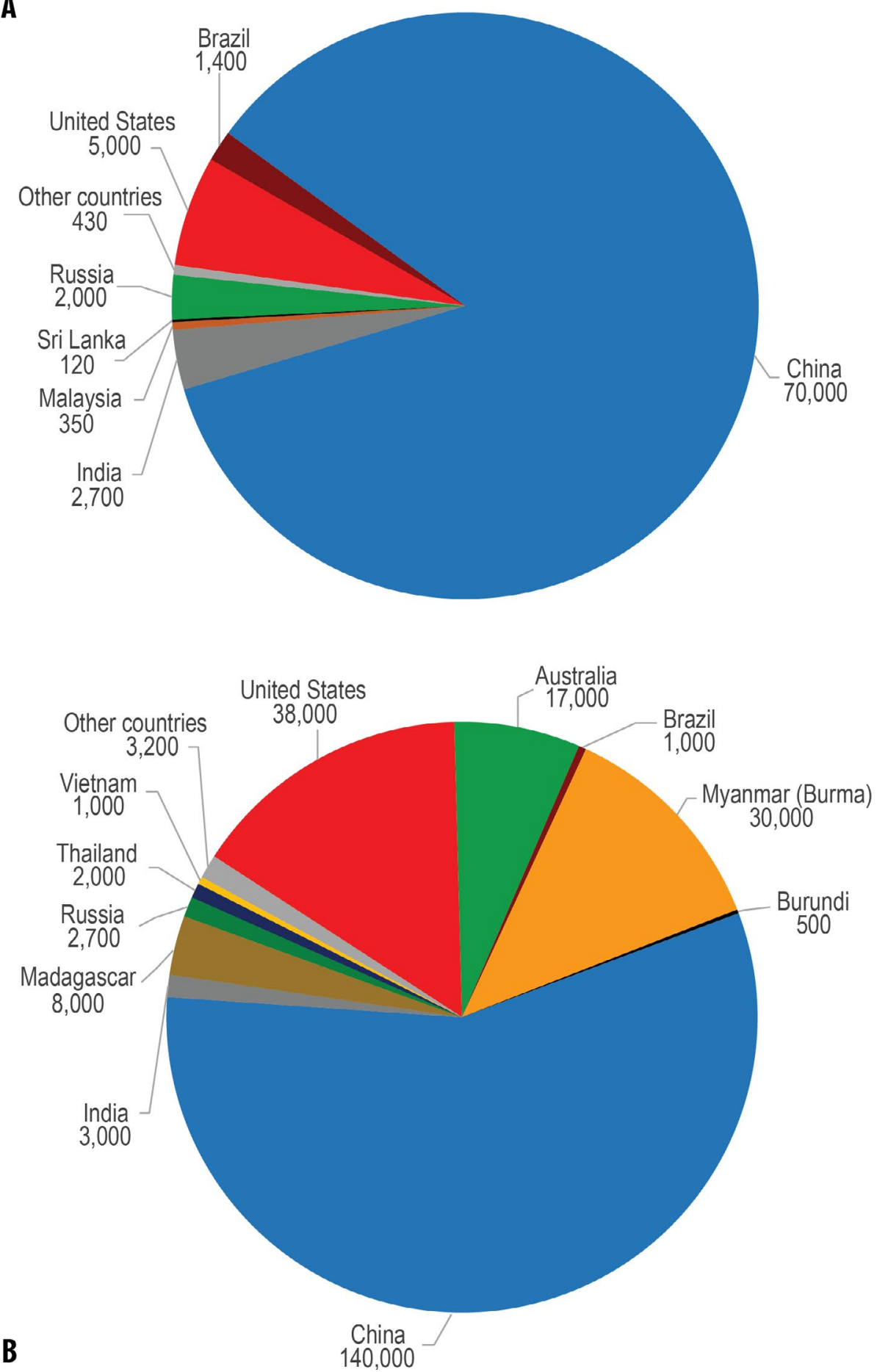

Figure 6. Pie diagrams showing global rare earth element (earth oxides equivalent) production in metric tons in 2000 (A) and 2020 (B) (compiled from USGS, 2021ab). 


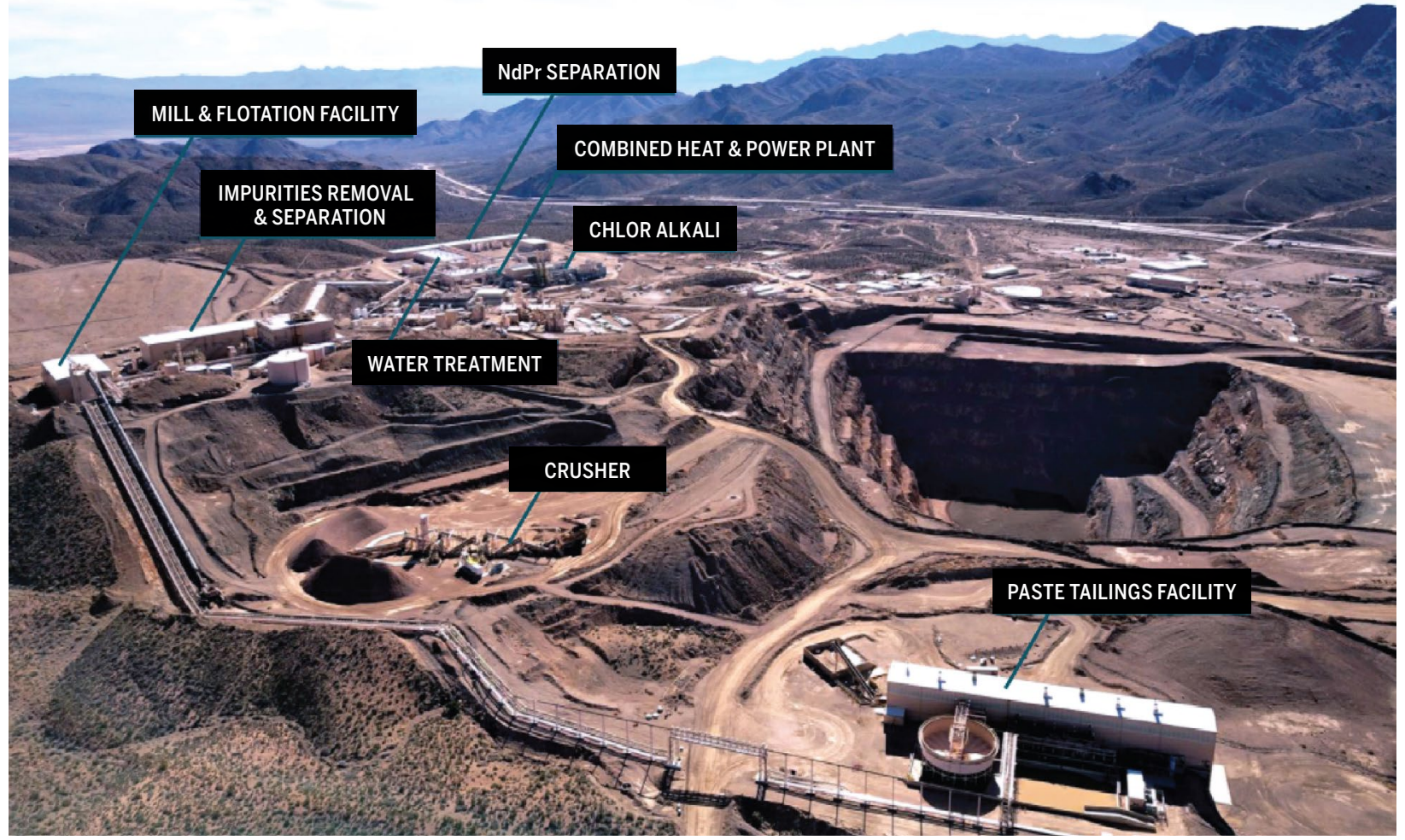

Figure 7. Photograph of the Mountain Pass Rare Earth Mine and Processing Facility in California. Photo by MP Materials.

\section{RARE EARTH ELEMENT MINING IN THE UNITED STATES}

Despite increased mining of REEs in the United States, domestic production in 2020 reached only about 38,000 tons of rare earth oxides, accounting for about $16 \%$ of global production (Figure 6B). The rare earths come mainly from bastnäsite and monazite concentrates in the Mountain Pass Mine in California, the only REEs mining and processing facility in the United States (USGS, 2021b; Figure 7).

The Mountain Pass mine, located about 50 miles from Las Vegas in Nevada, began production of REEs in 1952 from 1.4-billion-year-old Precambrian carbonatite intruded into gneiss. Until the 1990s when Chinese suppliers started to dominate the markets, the mine was a global leader in rare earths mining. After a series of ownership changes, environmental disasters, restrictions, and competition from China, the mine closed in 2002 (MP Materials, 2021; USGS, 2021b; Figure 5).

In 2008, the Mountain Pass was acquired by an investor group with plans to reopen and expand operations. Obtained investments allowed the mine to restart in 2012, but just three years later, the company filed for bankruptcy, and in 2015, the mine was shut down. Eventually, the mine was acquired out of bankruptcy and resumed min- ing and refining operations in 2018. In 2020, REE production reached the mine's all-time high, and operations are expected to expand (MP Materials, 2021).

Because current domestic production does not supply national needs, and the recycling of rare earths is limited, the United States is forced to import large quantities of REEs from other countries. In 2020, the United States imported 6,796 tons of earth oxides valued at US $\$ 110$ million. Most of the materials came from China $(80 \%)$, Estonia (5\%), Japan (4\%), and Malaysia (4\%) (USGS, 2021b). To meet ambitious goals of switching to green energy, the United States will need 20 to 25 times more REEs by 2050 (Koetsier, 2021). This puts incredible pressure on the industry and researchers to explore new sources of REEs and improve extraction methods. Many of these projects are government-sponsored and include assessing and cataloging REE resources in United States coal basins; developing strategies for minerals' recovery from coal, coal ash, coal refuse and wastewater streams; and deploying new technologies for state-of-the-art separation and mineral extraction (DOE, 2021).

\section{THE FUTURE OF RARE EARTH ELEMENTS}

It is expected that rare earth elements will not only remain an important part of our future, but that their use 
will increase with the push for electric vehicles and green energy. Although new processing technologies have been improving, the scarcity of the resource, the high cost of mining and refining, and growing demand have been driving the prices of REEs up. The rare-earths metal market is projected to grow from US $\$ 5.3$ billion in 2021 to US $\$ 9.6$ billion in 2026 at the compound annual growth rate of 12.3\% (Market Analysis Report, 2021).

Major growth is especially projected in the neodymium oxide segment needed to produce magnets found in planes, cars, wind turbines, and electronics like headphones, microphones, and computer discs. The price of neodymium oxide of US $\$ 49,763$ per metric ton in 2020 is expected to rise to US $\$ 77,500$ in 2025 . Also, the "phosphor segment" (europium, terbium, and yttrium) is projected to expand as incandescent lightbulbs are being replaced with fluorescent and LEDs due to policies in the United States, Canada, and the European Union (Balaram, 2019; Market Analysis Report, 2021; Science History Institute, 2021; Stormcrow, 2021).

Due to rapidly growing consumption and industrialization, China and other countries in the Asia-Pacific region are expected to hold their dominance on the REE market in the nearest future. Because of the importance of REEs and Chinese supremacy in the market, many nations, including the United States, consider the supply of rare earth elements as a matter of national security. It should be therefore expected that many new REE mines and processing plants will be opened around the world, and researchers and industry will be looking for new sources of rare earths. Currently, the focus is directed on coal waste, acid wastewater from abandoned mines, deep-sea mining, and extracting REEs from fertilizer byproducts. Ideas for increasing the supply include also designing microbes to efficiently separate the elements from the ore and even using extraterrestrial resources on the moon or Mars. While these new techniques require refining and are not currently economically viable, they may likely become feasible in the future with technological innovations and government support (Balaram, 2019; EPA, 2012; Jowitt, 2018; Market Analysis Report, 2021; Mastalerz et al., 2020; MiningDotCom, 2021; Science History Institute, 2021; U.S. Department of Defense, 2021).

As the global supply of REEs is limited by the cost and complexity of exploring, there is also a growing push for manufacturing products to contain smaller amounts of rare earth elements and designing products to allow for easier repair and upgrade rather than discarding. Scientists and industry are looking for REE substitutes and trying to develop a better recycling methodology to recover rare earth elements from electronic waste like flat-panel screens and batteries. This is, however, very challenging, as many of the products contain only small and difficult-to-extract amounts of REEs. For instance, recycling 100,000 iPhones can salvage only about $11 \mathrm{~kg}$ of REEs. While the current recycling rate is less than 5\%, reutilization has a potential for growth especially if supported by consumers and manufacturers (Balaram, 2019; Jowitt, 2018; Market Analysis Report, 2021; Science History Institute, 2021; Voncken, 2016).

Another important issue that will influence REEs' future is the impact of REE mining and refining on the environment and human health. The extraction of rare earths produces a significant amount of often toxic and radioactive materials that have the potential to cause contamination (EPA, 2012). One of the most drastic examples is a manmade lake near the biggest REE mine in the world, Bayan Obo in Inner Mongolia, considered to be one of the most dangerous places in the world due to its massive pollution levels. The negative environmental impacts of REE mining activities and processing also can be seen in the United States, Brazil, India, and Malaysia (Balaram, 2019; Pan and Li, 2016). It is therefore important that as we search for alternative sources and increase REE production, the ecosystem is protected.

\section{REFERENCES}

Balaram, V., 2019, Rare earth elements-A review of applications, occurrence, exploration, analysis, recycling, and environmental impact: Geoscience Frontiers 10 (4) 12851303. doi: 10.1016/j.gsf.2018.12.005

Jowitt, S.M., 2018, Criticality of the rare earth elementsCurrent and future sources and recycling. Mdpi AG, ISBN-10: [3038970174, <https://www.mdpi.com/journal/ resources/special_issues/criticality_rare_earth_elements $>$.

King, H.M., 2021, REE - Rare earth elements and their uses, $<$ https://geology.com/articles/rare-earth-elements>, date accessed, November 14, 2021.

Koetsier, J., 2021. US needs 10x more rare earth metals to hit Biden's electric vehicle goals: Forbes. $<$ https://www. forbes.com/sites/johnkoetsier/2021/09/29/us-needs-10xmore-rare-earth-metals-to-hit-bidens-electric-vehiclegoals/?sh=2a161ab3e41d $>$, date accessed, November 17, 2021.

Mastalerz, M., Drobniak, A., Eble, C., Ames, P, McLaughlin, P., 2020, Rare earth elements in Pennsylvanian coals and shales in the eastern part of the Illinois Basin: International Journal of Coal Geology 231 (2020) 103620. doi: 10.1016/j.coal.2020.103620 
Market Analysis Report, 2021, Rare-earth metals market by (lanthanum, cerium, neodymium, praseodymium, samarium, europium, \& others), and application (permanent magnets, metals alloys, polishing, additives, catalysts, phosphors), region - global forecast to 2026: Report MM 7863, < https://www.marketsandmarkets.com/Market-Reports/rare-earth-metals-market-121495310.html>.

MiningDotCom, 2021, Extracting rare earths from fertilizer byproduct may soon be a reality, $<$ https://www.mining. com/extracting-rare-earths-from-fertilizer-byproduct-may-soon-be-a-reality/>, date accessed, November $18,2021$.

MP Materials, 2021, <https://mpmaterials.com/>, date accessed, November 17, 2021.

Pan, Y., Li, H., 2016, Investigating heavy metal pollution in mining brownfield and its policy implications-A case study of the Bayan Obo rare earth mine, Inner Mongolia, China: Environmental Management 57, 879-893. doi: 10.1007/s00267-016-0658-6

Science History Institute, 2021, Science matters-The case of rare earth elements, <https://www.sciencehistory.org/ learn/science-matters/case-of-rare-earth-elements-history-future>, date accessed, November 16, 2021.

Stormcrow, 2021, Rare earths report, $<$ https://www.stormcrow.ca/wp-content/uploads/2021/03/20210308-Stormcrow-UCore-Initiation-Final.pdf $>$.

U.S. Department of Defense, 2021. DARPA looks to microbes to process rare earth elements, $<$ https://www. defense.gov/News/News-Stories/Article/Article/2768268/ darpa-looks-to-microbes-to-process-rare-earth-elements>, date accessed, November 17, 2021.

U.S. Department of Energy (DOE), 2021, Department of Energy awards \$19 million for initiatives to produce rare earth elements and critical minerals, $<$ https://www.energy.gov/articles/doe-awards-19-million-initiatives-produce-rare-earth-elements-and-critical-minerals $>$, date accessed, November 16, 2021.

U.S. Environmental Protection Agency (EPA), 2012, Rare earth elements--A review of production, processing, recycling, and associated environmental issues, PA 600/R-12/572, <https://nepis.epa.gov/Exe/ZyPURL. cgi?Dockey $=$ P100EUBC.txt $>$.

USGS 2021a, United States Geological Survey National Minerals Information Center, Rare earth statistics and information, $<$ https://www.usgs.gov/centers/nmic/rare-earths-statistics-and-information>.

USGS 2021b, United States Geological Survey Mineral Commodity Summaries 2021, <https://pubs.usgs.gov/ periodicals/mcs2021/mcs2021.pdf $>$.

USGS, 2014, United States Geological Survey Mineral Resources Program, The rare-earth elements - vital to modern technologies and lifestyles, Fact Sheet 2014 -3078, <https://pubs.usgs.gov/fs/2014/3078/pdf/fs20143078.pdf>.
USGS, 2005, United States Geological Survey, Rare earth elements -- critical resources for high technology: U.S. Geological Survey Fact Sheet 087-02, <https://pubs.usgs. gov/fs/2002/fs087-02>.

Voncken, J.H.L., 2016, The rare earth elements-an introduction: SpringerBriefs in Earth Sciences, Springer (1st ed.) ISBN-10: [3319268074, <https://link.springer.com/ book/10.1007/978-3-319-26809-5>. 